Founder bows out as genomic firm slashes workforce

Meredith Wadman, Washington

Human Genome Sciences (HGS), a biotechnology company that epitomized the promise of genomic medicine, is laying off 200 of its 1,000 employees and parting ways with its charismatic chief executive, William Haseltine.

Haseltine says that he was the one who initiated his retirement from the company, which is based in Rockville, Maryland. The former Harvard AIDS researcher, who founded the company in 1992, says his skills are not the commercial ones now needed to make drugs available for patients. HGS board members confirm that Haseltine was not ousted.

The company also announced on 25 March that it was jettisoning several drugs in early-stage development to focus on its five most promising candidates, which include LymphoStat-B for rheumatoid arthritis and systemic lupus erythematosus - now in phase II trials.

Some industry observers say the changes in the company, which follow a cut of $7 \%$ of employees last December, are normal for a biotech company as its drugs near commercialization. "It is just a natural part of the evolution of a company in drug development," says Robert Eaton, president of MdBio, a nonprofit organization that supports biotechnology in Maryland.

Others disagree. "Things are getting tough at HGS and Haseltine's leaving the ship when it looks as though there are reefs in the distance," says Alan Walton at venture-capital firm Oxford Bioscience Partners in Westport, Connecticut, who helped launch HGS.

HGS has $\$ 1.3$ billion in cash, but still lacks a drug close to commercial launch. Its shares, of which Haseltine owns 6 million, are worth $\$ 12$, compared with \$232 at their peak in March 2000.

Haseltine's departure echoes that of his long-time rival Craig Venter who left Celera Genomics, also based in Rockville, in January 2002. Both men are aggressive scientific entrepreneurs who seduced Wall Street with high profit expectations that are so far unfulfilled. Their rivalry developed during a contentious partnership between HGS and The Institute for Genomic Research, a nonprofit research organization founded by Venter, which ended in 1997.

The HGS board plans to hire a chief executive by the autumn and already has a list of candidates. Haseltine will retire once his successor is named.

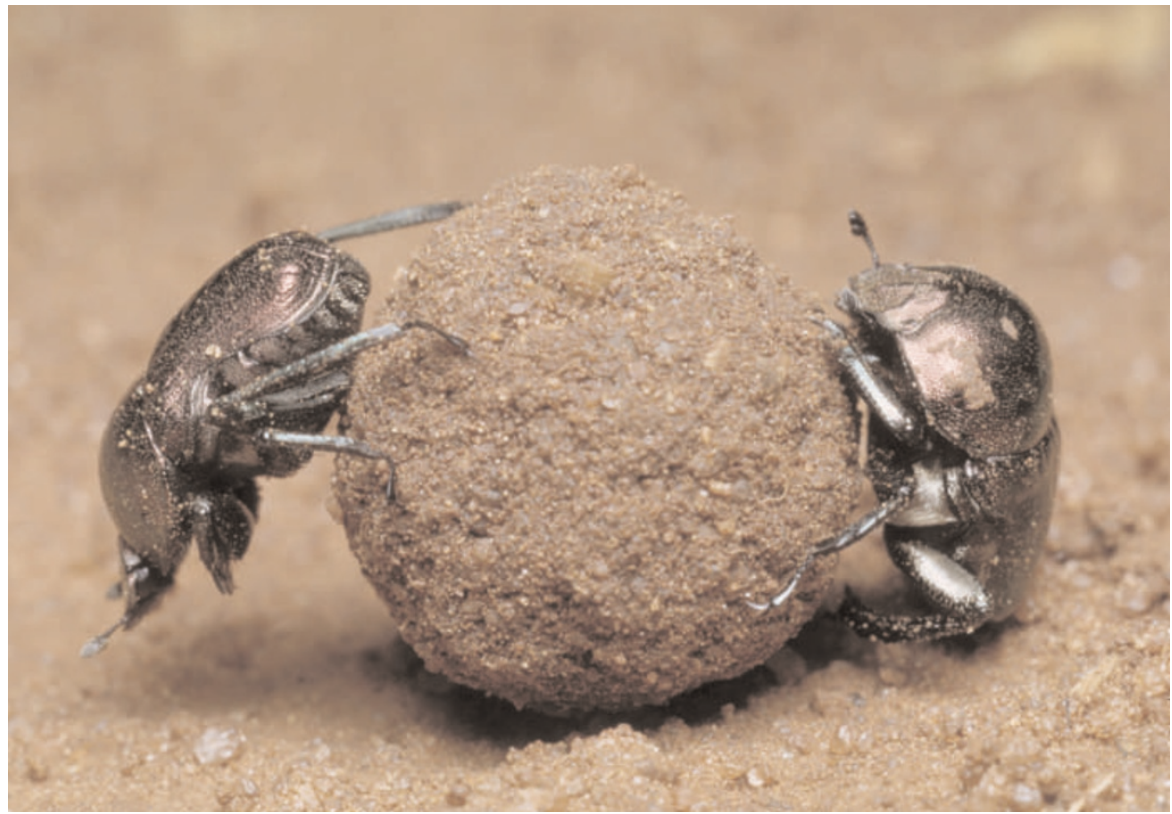

Bottom of the heap: dung beetles and other lowly life-forms struggle to mount conservation agendas.

\title{
Biologists get ball rolling to aid neglected invertebrates
}

Helen Pearson, New York

Conservation biologists are drawing up a comprehensive plan for the preservation of invertebrates — populous but overlooked inhabitants of the animal world.

Ranging from beetles to jellyfish, invertebrates make up 90-95\% of Earth's animal species and form food for much of the remainder. Although the exact numbers under threat are unknown, habitat destruction, pollution, invasive species and climate change are driving numerous species towards extinction.

Many researchers are aware of the plight of invertebrates, but such organisms have struggled to gain a foothold in conservation agendas. For example, only 189 species of invertebrate are listed as threatened or endangered under the US Endangered Species Act, less than $40 \%$ of all the animal species listed. And with very few additional species now being added to that list (see Nature 426, 592; 2003), the prospect of adding uncharismatic flies and worms seems to be remote.

Now 300 invertebrate researchers, policymakers, conservation project managers, and representatives of non-governmental organizations have met to discuss the issues facing invertebrate conservation. The Expanding the Ark symposium, which took place on 25 and 26 March at the American Museum of Natural History in New York, was extended when some 25 participants decided to form a consortium that will act as an advocacy group for these neglected species.

Experts at the meeting were concerned that creepy-crawlies are not as winsome as tigers and bears - yet public concern can be critical for a species to earn legal protection.

Researchers are also troubled that the vast majority of invertebrate species are unknown, unnamed or uncharacterized - and without this information it is hard to make a case for their protection. "We have not delivered the data to make invertebrate conservation possible," says Sacha Spector, who helped to organize the meeting and studies invertebrates at the American Museum of Natural History.

Spector says the consortium plans to produce two documents this year. The first will draw together published data on the decline in invertebrate species in order to advertise their plight. The second will draw up a set of recommendations for reversing the decline, which will be aimed at scientists, conservation groups, educators and policy-makers.

Details are still being discussed but the recommendations will include better ways to collect and access biodiversity data, such as collaboration with amateur conservationists. "We'll be very interested in that," says Dan Ashe, science adviser to the director of the US Fish and Wildlife Service, which enforces the Endangered Species Act.

The paper is also likely to advocate economic evaluations. According to a study presented at the meeting by entomologist John Losey of Cornell University in Ithaca, New York, insects alone provide services worth $\$ 65$ billion a year in the United States: decomposing dung, pollinating crops, and eating pests.

Whether or not the paper really makes an impact, delegates at the meeting say it will show that the invertebrate conservation community is getting its act together. "This is the first time that something like this has started to gel," says Scott Hoffman Black, executive director of the Xerces Society, a conservation group in Portland, Oregon. 